\title{
Analysis of container dwell time on marine terminal throughput and rehandling productivity
}

\author{
Nathan Huynh ${ }^{*}$
}

\begin{abstract}
When port authorities or terminal operators set the free time or increase storage density, the decision is often made without a clear understanding of their effects on throughput and rehandling productivity. This is partly because practical methods that deal specifically with the effect of dwell time on throughput and productivity are limited in the literature; hence the motivation for this work. This paper introduces simple methods to evaluate the effect of container dwell time and storage policies on import throughput, storage density, and rehandling productivity. The analysis considers two import storage strategies 1) non-mixed - no stacking of new import containers on top of old ones, and 2) mixed - stacking of new import containers on top of old ones. The results highlight the effect dwell time has on throughput and rehandling productivity. For the non-mixed storage policy, the increasing container dwell time lowers throughput and average stack height - resulting in an increase in rehandling productivity. On the other hand, for the mixed storage policy, the increasing container dwell time raises throughput and average stack height - resulting in a decrease in rehandling productivity. Using the presented methods, port authorities and terminal operators are able to assess and quantify the benefits of their decisions regarding container free time and subsequently make an informed decision.
\end{abstract}

Keywords: container, marine terminals, dwell time, throughput, rehandling productivity, Monte Carlo Simulation. 


\section{Introduction}

In late 2006, the Transportation Research Board TR News (2006) was dedicated to the intermodal container era - its history, security and trends. An article in that edition examining the contribution containerization has made to global trade growth reported that "according to Global Insight, Inc., global containerized trade has grown at a compound rate of 12 percent from 2001 to 2005 and is projected to grow at 6.5 percent to 2011 '". Translating global growth estimates such as these to specific port terminals, however, is more problematic. Indeed projections of containerized trade were recently described as "black magic" in a recent article (Leach, 2007) citing, amongst other supply-side factors, lack of data on vessel capacity, terminal efficiencies and vessel speeds. Nevertheless, all the maritime industry recognize that container volumes on the global trade routes have continued to grow and exhibit "shocks" from time to time which create stress at port container terminals. As an example, while container volumes in 2004 increased more than $12 \%$ in the AsiaNorth America trade lane, they rose by $17 \%$ in the Asia-Europe trade lane (Leach, 2007) - creating higher demand than predicted for the ports on the latter lanes. Furthermore, some ports were initially rather slow to react to the rise in volumes, creating congestion in the shipside-terminallandside link which negatively impacted the supply chain.

As a consequence, substantial recent effort has been expended by port authorities to enhance their marine container terminal operations. Many U.S. terminals cannot easily add additional berths and container terminals because there is little easily available room for expansion. Building "greenfield" terminals is becoming more challenging with rising construction cost, growing environmental permitting issues, and the need to address environmental justice issues. For these reasons, terminal operators first look for ways to boost throughput and productivity. These strategies include introducing new and improve existing technologies, use of chassis pooling, reducing container dwell time, increasing storage density, blocking containers, and extending gate hours (Huynh, 2006).

A commonly used strategy by terminal operators to increase throughput is reducing the container dwell time, defined as the number of days a container remains in the terminal. This is accomplished by reducing container free time and increasing demurrage fees. Free time is the period during which a container can reside in the container yard without being assessed a demurrage fee. Since July 1, 2005, the Port of Long Beach has reduced its free time for import containers from five days to four and free time for export containers from seven days to six. Other ports such as New York-New Jersey, Vancouver, Washington, Los Angeles, and Houston have also reduced their free times in an effort to boost throughput (The Week, 2005).

Another commonly used strategy by terminal operators to increase throughput is increasing storage density. For imports, the storage density (i.e., yard storage productivity) can be increased by stacking containers higher and/or stacking recently unloaded (termed new) imports on top of those that are already in the yard (termed old). However, higher stacks, especially mixed ones, require additional rehandling (shuffling) of containers in retrieving the target container. The higher the number of rehandling moves associated with an import delivery to a road truck, the lower the rehandling productivity as defined below (equation 1). Rehandling productivity significantly affects truck turn time (the total time it takes a truck to complete its import or export transaction). 
Hence, terminal operators must balance storage density with rehandling productivity. With truck turn time being a prominent issue because of environmental concerns (Lowenthal, 2002), keeping truck turn time low is a high priority item for most terminals.

$$
\text { Rehandling productivity }=\frac{\text { Number of import deliveries }}{\text { Total number of import moves }}
$$

In practice, when port authorities or terminal operators set the free time or increase storage density, the decision is often made without a clear understanding of their effects on throughput and rehandling productivity. This is partly because practical methods that deal specifically with the effect of dwell time on throughput and productivity are limited in the literature and detailed analysis via simulation is too costly and time consuming. This paper seeks to shed light on this subject and deals specifically with yard throughput and rehandling productivity of imports.

In this work, the impact of container dwell time on yard import throughput and rehandling productivity are examined for two import storage strategies 1) non-mixed - no stacking of new import containers on top of old ones, and 2) mixed - stacking of new imports on top of old ones. With the non-mixed strategy, throughput and storage density are lower; however, rehandling productivity is higher. Some terminals employ the non-mixed storage policy in an effort to minimize rehandling. With the mixed strategy, throughput and productivity are higher although rehandling productivity is lower. Terminals that are space constrained typically employ the mixed storage strategy.

To facilitate the analysis, this paper introduces simple methods to evaluate the effect of container dwell time and storage policies on import throughput, storage density, and rehandling productivity. To estimate the expected number of rehandles when delivering an import container to a road truck, a Monte Carlo Simulation (MCS) method is utilized. Monte Carlo simulation is a method for iteratively evaluating a deterministic model using sets of random numbers as inputs. There are three important reasons for employing the MCS method. First, it allows us to make conclusions about the variance of the expected rehandles as a function of stack height and storage strategies. Second, it allows us to conveniently solve for ad hoc rehandling strategies (unique rehandling strategies employed by Barbours Cut Container Terminal when the bay is full). Third, it circumvents the need to make restrictive assumptions regarding the probability of containers of being delivered to road trucks. In essence, MCS provides a robust way of estimating the number of rehandles.

Section 2 describes the container yard layout and type of handling equipment considered in this work. Section 3 reviews related published studies. Section 4 introduces methods for the analysis. Section 5 discusses the various experiments and their results. Lastly, section 6 summarizes the work performed and provides concluding remarks. 


\section{Background}

Most present-day container terminals stack their containers (Hicks, 2005) rather than store them on chassis. A typical block is shown in Figure 1a where a block is divided into bays. 20-foot containers occupy one bay and 40-foot containers occupy two bays. In most practices, containers of 20 and 40 feet are not mixed within a bay. A slot in each bay is identified by the row letter and the tier number. For example, A1 would indicate the slot in row A and tier 1. Row A is the row next to the truck lane. A stack refers to a set of containers in a row.

(a)

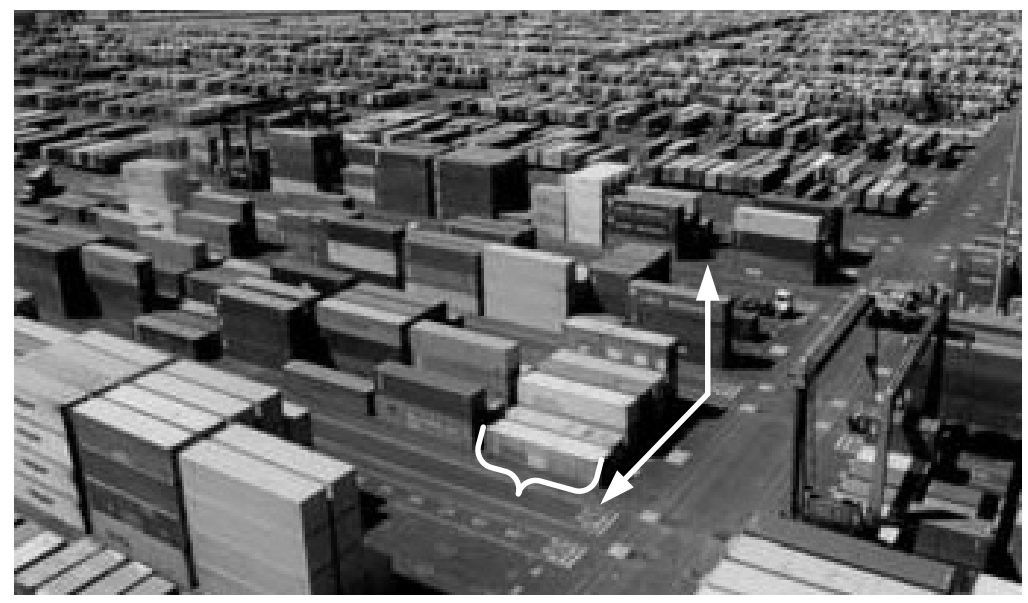

(b)

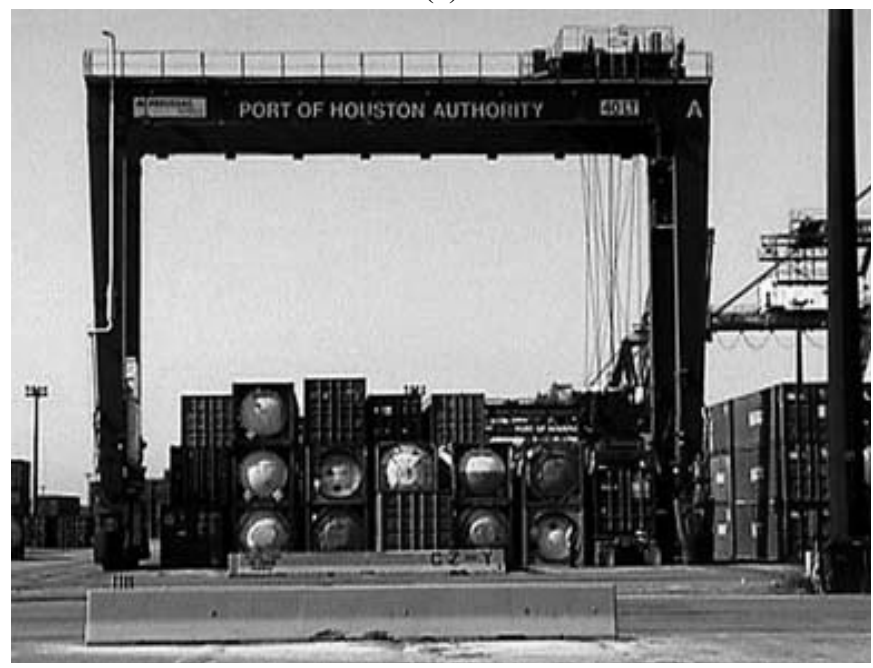

Figure 1. a) Top - Configuration of a container block,

b) Bottom - Section view of bay with RTG 
Stacking saves space; however, requires rehandling effort and time. To retrieve a bottom container, those containers on top must first be rehandled. The type of handling equipment considered in this work is a rubber-tired gantry (RTG) crane. The most common-size RTG spans across six rows and allows 1-over-4 operation where one container can be lifted over a stack four containers high. Figure $1 \mathrm{~b}$ shows how an RTG operates in a bay. Each bay must allow enough space for rehandling due to the 1-over-4 limit and because an RTG cannot move efficiently with a container from one bay to the next. A bay with 6 rows and 4 tiers will typically have less than 24 containers and at the Port of Houston Authority's Barbours Cut Container Terminal (BCT) and Bayport Terminal (BPT), the number of containers that can be stored in a 6-by-4 bay is capped at 21 .

\section{Literature review}

The seminal work dealing specifically with container dwell time and throughput is that performed by Dally et al. (1977). Their work showed the advantages that a reduction in average dwell time could have on container throughput (capacity). Most importantly, this work was the first to propose a throughput capacity model (equation 2) from a supply standpoint.

$$
C=\frac{L \times H \times W \times K}{D \times F}
$$

where $\mathrm{L}$ is the number of TEU container spaces on the ground, $\mathrm{H}$ is the mean profile height to which containers are stacked, $\mathrm{W}$ is the working slots in the container storage area, $\mathrm{K}$ is the total number of days in the period, $\mathrm{D}$ is the mean container dwell time, and $\mathrm{F}$ is the peaking factor.

Subsequently, several studies in the planning area have proposed models similar to equation 2. Dharmalingam (1987) made a slight modification to equation 2. Itsuro (1991, 2001) proposed a different model. More recently, Chu and Huang (2005) proposed a model that can be used to determine terminal capacity based on the adopted yard handling system. This paper introduces expressions to determine the effective throughput based on services' pro forma and volume. In relation to this study, Equation 2 is useful for comparison purposes and its values serve as upper bounds or limits on what the terminal can effectively handle.

In the area of container rehandling, few studies have proposed methods to estimate the expected number of rehandles. McDowell et al. (1985) proposed a recursive method for estimating the rehandles, and they developed a computer program to perform the calculations. Watanabe (1991) proposed some practical equations to address the same problem. Kim (1997) extended Watanabe's work and provided tables and more accurate equations. Castilho and Daganzo (1993) provided a different set of equations in their work that addressed handling strategies for import containers. None of these works allows for ad hoc rehandling strategies, and they all require 
containers in a bay to have equal probability of being selected.

\section{Methodology}

This section first introduces concepts, terminology, and notations. Then, it presents simple expressions that can be used to compute import throughput. Lastly, how the MCS method is applied to estimate the number of rehandles is described.

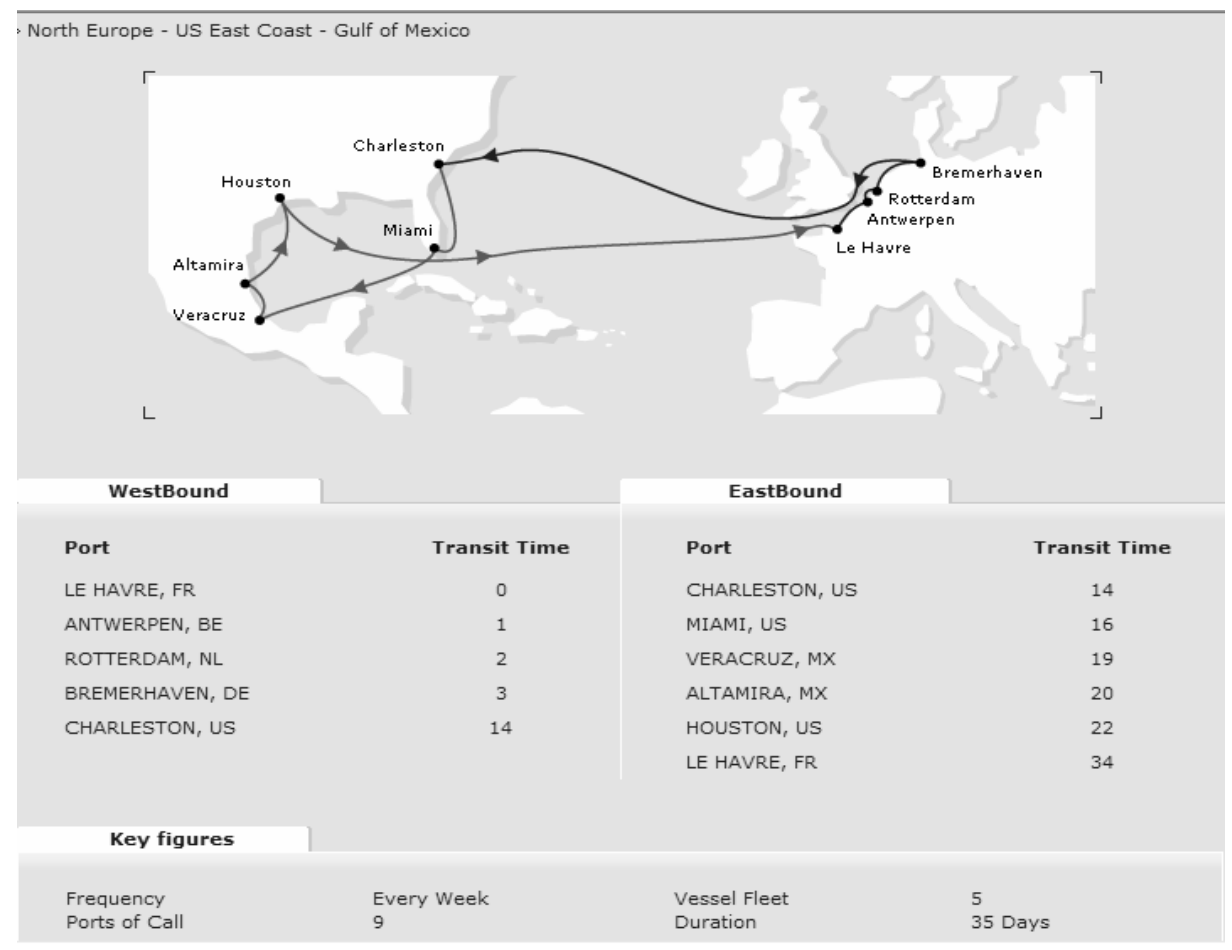

Source: http://www.cma-cgm.com/eBusiness/Schedules/LineServices/ServiceSheetaspx?ServiceCode=VICTORY

Figure 2. CMA-CGM Victory Bridge service

Ocean carriers use various liner services, $S$, to transport goods along specific trade corridors and ports. A service has a set of ports it must visit with a predefined pro forma, $P_{s}$, using $N$ vessels. As shown in

Figure 2, this steamship company serves the North Europe, US East Coast, and Gulf of Mexico trade corridor and it is set to call nine ports with a pro forma of 7 days. To meet this schedule, five vessels are used. 
Typically, services and associated vessels and port of calls are already set up in the operator's terminal operating system (TOS). So, in day-to-day operations, when a vessel from service $S$ calls, all the terminal operator needs to do is assign a voyage $i$ to the vessel. The ith inbound/ outbound voyage of service $s$ is denoted as $i_{s}$. Once a voyage is assigned, the next step for the terminal operator is to specify the vessel's schedule. Information required at this stage are 1) berth, 2) vessel's estimated time of arrival, 3) vessel's estimated time of departure, 4) the begin receiving date for export containers, and 5) the cutoff date for receiving export containers. If $D_{s}$ denotes the time of the very first voyage for service $s$, then the departure time of the ith voyage of that service can be computed as $D_{s}+\left(i_{s}-1\right) P_{s}$. For example, if $D_{s}$ for a service is $t$ on day 0 and $P_{s}=7$ days (i.e. weekly service), then the departure time of the 1st voyage is $t$ on day $0[\mathrm{t}+(1-1) 7=\mathrm{t}+0]$. Similarly, the departure time of the 2 nd voyage is $t$ on day $7[\mathrm{t}+(2-1) 7=\mathrm{t}+7]$, the 3 rd voyage is $t$ on day 14, and so on. Note that the notations make no distinction between vessels within a service. It is irrelevant to the terminal and customers which vessel is being used. All that matters is that the service meets its pro forma.

A service is designed to unload a relatively constant number of TEUs at each terminal. The volume to be unloaded is denoted as $B_{s}^{i m p}$. The proportion of import containers that are delivered with $\mathrm{x}$ dwell days after the vessel's departure is denoted as $F_{s}^{\text {imp }}(x)$.

The cumulative number of import containers unloaded to the container yard at time $t$ for all services $(S)$ can be computed using the following expression (equation 3). Thus, the annual yard throughput for imports is $U(365)$. The technical definition of yard throughput is TEUs per year/gross acre (National Research Council, 1986). However, in this paper, we will use the term throughput simply to indicate the TEUs handled per year. This is done to avoid misrepresenting a container's productivity because throughput is often reported differently and gross acre is counted differently by different terminals.

$$
U(t)=\sum_{s=1}^{S} \sum_{i=1}^{i_{s}} B_{s}^{i m p} H\left(\left(t-\left(D_{s}+(i-1) P_{s}\right)\right)\right)
$$

where $i_{s}$ is the maximum ith voyage of service $s$ up to time $t$. That is, $\left(i_{s} \cdot P_{s}\right)<t$. H is a unit step function, defined as:

$$
H(n)=\left\{\begin{array}{l}
0, \mathrm{n}<0 \\
1, \mathrm{n}=0
\end{array}\right.
$$

Equation 4 computes the cumulative number of delivered imports for all services $(S)$ at time $t$.

$$
\left.D(t)=\sum_{s=1}^{S} \sum_{i=1}^{i_{s}} B_{s}^{i m p} F_{s}^{i m p}\left(t-\left(D_{s}+(i-1) P_{s}\right)\right)\right)
$$


The number of import containers in the yard at the start of day $t$ is $Y(t)=U(t)-D(t-1)$, assuming import containers are unloaded first before they can be delivered to road trucks. Hence, the daily average stack height is:

$$
\overline{\text { Stack Height }(t)}=\frac{Y(t)}{\text { total number of one-tier high 20-foot container ground slots }}
$$

As mentioned, the yard import throughput and storage density can be increased by stacking containers higher and/or by employing the mixed storage policy. However, the rehandling productivity will be diminished. The expected number of rehandles $(\mathrm{R})$ can be evaluated as follows.

$$
E[R]=\sum_{i=1}^{a} \sum_{j=1}^{c_{a}} p_{i, j} \cdot r_{i, j}
$$

where $C_{a}$ denotes the height of stack $a, p_{a c}$ denotes the probability that container in position $(a, c)$ is selected, and $r_{a, c}$ is the number of rehandles required to retrieve the target container in slot $(a, c)$.

A Monte Carlo Simulation method is used to solve equation 5 for three important reasons. First, it allows conclusions about the variance of the expected rehandles as a function of stack height and storage strategies to be made. Second, it conveniently solves ad hoc rehandling strategies. Third, it circumvents the need to assume all containers in a bay have equal probability of being selected.

(a)

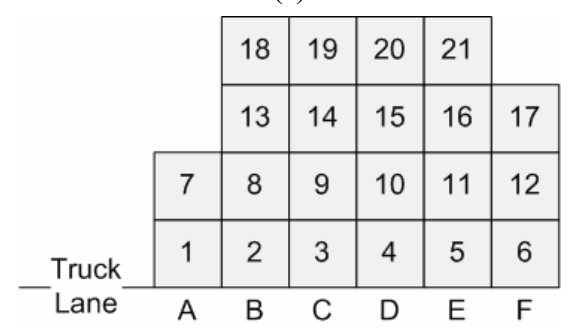

(b)

Tier 4

Tier 3

Tier 2

Tier 1

$\begin{array}{cccccc}\text { Stack A } & \text { Stack B } & \text { Stack C } & \text { Stack D } & \text { Stack E } & \text { Stack F } \\ & 0 & 0 & 0 & 0 & \\ & 1 & 1 & 1 & 1 & 0 \\ 0 & 3 & 3 & 3 & 3 & 2 \\ 1 & 5 & 5 & 5 & 5 & 4\end{array}$

Figure 3. a) Top - Configuration of a full bay,

b) Bottom - Number of rehandles associated with each slot when bay is full 
Figure 3a shows the configuration of a full bay at Barbours Cut terminal (BCT). As a rule, BCT always leave $(c-1)$ open spaces in the bay. This is because with their 1-over-4 RTG operations, $(c-1)$ spaces must be kept open to allow the RTG to shuffle containers to access the bottom container of each stack. Another reason why open spaces must be kept open in the bay is because as a safety rule RTGs are not permitted to gantry (travel across bays) with a container. BCT never leaves any container in A3 and A4. Their RTG operators have a history of knocking containers in these slots on to the waiting truck. Therefore, to avoid such mishaps, RTG operators are instructed never to leave any container in these slots. As a result of such decision, whenever the bay is full and a bottom container needs to be retrieved, the actual number of rehandles is higher than what is typically considered in the literature (e.g., Kim, 1997, Castilho and Daganzo, 1993). With MCS, this can easily be addressed by defining the associated number of rehandles for every container in the bay. Figure $3 \mathrm{~b}$ shows how this can be accomplished.

Assume there is a full bay as shown in Figure $3 \mathrm{a}$ and all containers are equally likely to be selected for delivery. The true expected value, using equation 5 , is 2.05 . The number of rehandles that occur on a given day can be estimated using MCS by randomly selecting one of the 21 containers in the bay utilizing a uniform distribution. Depending on which container is selected, the associated number of rehandles is derived as illustrated in Figure 3b. If, for example, the selected container is container 2 (refer to Figure 3a), then the number of rehandles is 5 - before delivering 2: move 18 to $\mathrm{A} 3,13$ to $\mathrm{A} 4$, and 8 to F4; after delivering 2, move 13 to $\mathrm{B} 1$ and 18 to $\mathrm{B} 2$. A sample size of 500 is assumed for this example. The number of rehandles for each of the 500 containers is first derived and then an average is calculated. This average would be the estimated number of rehandles for one repetition. To obtain the sample average and variance, the experiment would be repeated over many repetitions. Trial experiments show that it would take about 10,000 repetitions to provide a good estimate.

Figure 4a shows the MCS results for the expected number of rehandles when a bay is full with ad hoc rehandling strategies and equal probability of selecting a container in the bay.

A crucial part of the MCS method is the random number generator. In this paper, even though Microsoft Excel 2003 is used as the platform to run the MCS experiments, Excel's intrinsic RAND and VBA's Rnd functions were not used. Instead, the random number generator RANDOM developed by Barreto and Howland (2005) was employed because the RAND and Rnd functions have too much structure embedded in them and not enough randomness. 


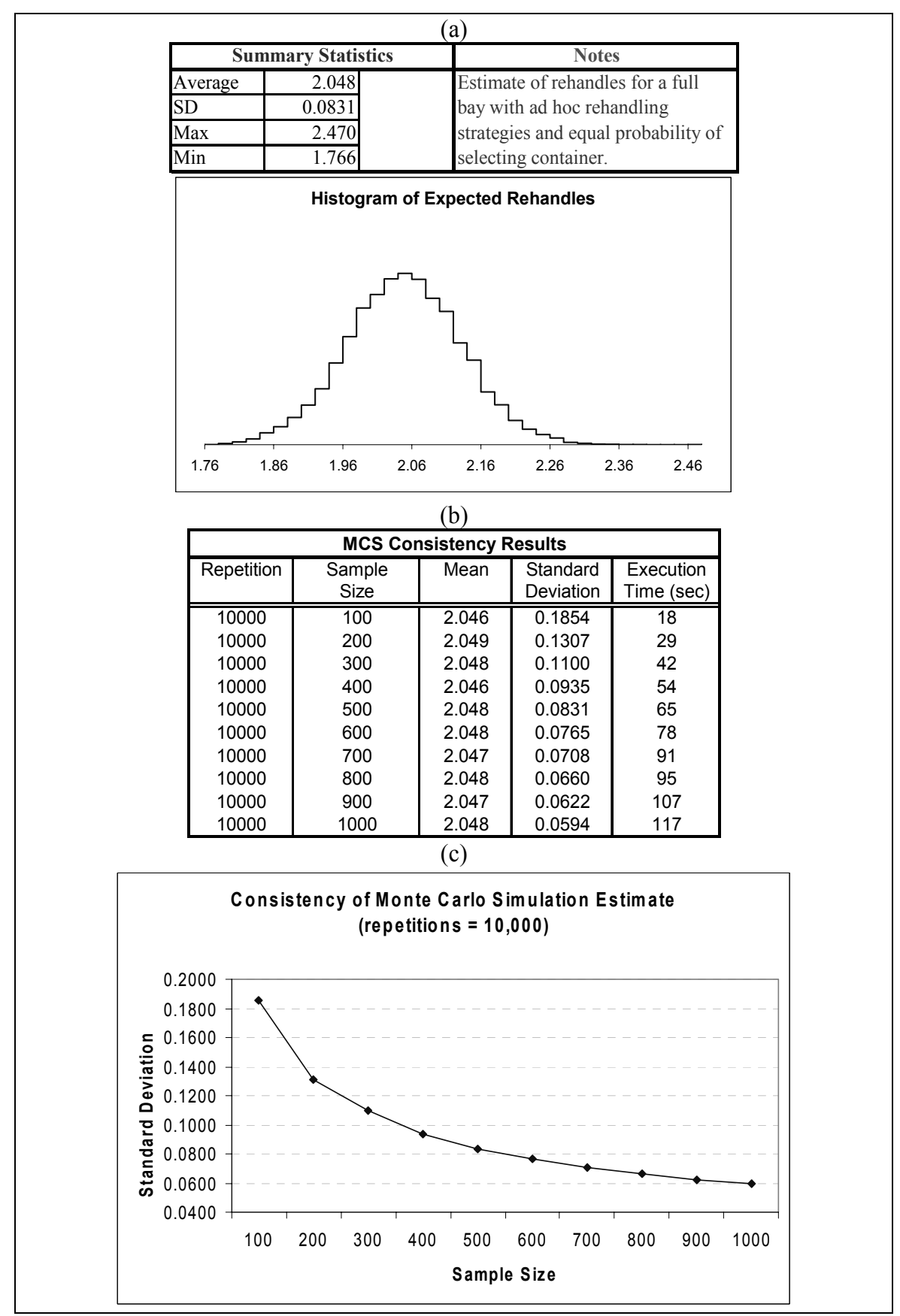

Codes that generate statistics and histogram were developed by Barreto and Howland [17]

Figure 4. a) Top - MCS results for estimating the expected number of rehandles,

b) Middle - Consistency of MCS Estimate,

c) Bottom - Consistency of MCS estimate in graphical form 
Figure $4 \mathrm{~b}$ and Figure $4 \mathrm{c}$ demonstrate that the MCS method is a consistent estimator of the expected number of rehandles in the full bay example; a consistent estimator of a parameter is one whose sampling distribution becomes ever more tightly concentrated around the true parameter value as the sample size increases. As shown, the standard deviation decreases as the sample size increases. That is, the sample distribution becomes more tightly concentrated around the true parameter value as the sample size increases. The MCS runs and their associated execution times were generated from a Dell Optiplex GX620 with a $3.40 \mathrm{Ghz}$ Pentium CPU and 2.00 GB of RAM. In subsequent experiments, a sample size of 1,000 and repetition of 10,000 were used as these values were found to yield good estimates without requiring much additional computation time.

\section{Analysis}

The methods introduced in the previous section are applied to several experiments to gain insight into the effects of container dwell time on import throughput and rehandling productivity. The experiments consider one container block with 33 bays, 6 rows, and 4 tiers for a total capacity of 693 TEUs (max of 21 TEUs per bay). This is a typical block size at BPT. The experiments assume import containers are delivered in equal proportions. Furthermore, they assume during the delivery the ad hoc rehandling strategy is used where the RTG operator must make additional rehandling moves to clear slots $\mathrm{A} 3$ and $\mathrm{A} 4$.

\section{Experiment Set 1 (non-mixed storage policy)}

\section{Experiment parameters:}

- 1 service: $D_{1}=0, B_{1}^{i m p}=693$ TEUs, and $F_{1}^{i m p}(x)=693 / P_{1}$.

- Dwell time dictates $P_{1}$. Thus, $P_{1}=$ dwell time.

- Vary $P_{1}(7,14,21,28$, and 35$)$.

The first set of experiments examines the effect of dwell time on throughput and rehandling productivity under the non-mixed storage policy. With this storage policy, once a designated area is allocated to a service for imports that space can only be used to store one vessel's imports from that service. The next vessel's import containers cannot be stored in the designated space until all the previous vessel's containers have been delivered to road trucks. Therefore, the service call frequency $\left(P_{l}\right)$ is dictated by the container dwell time. 


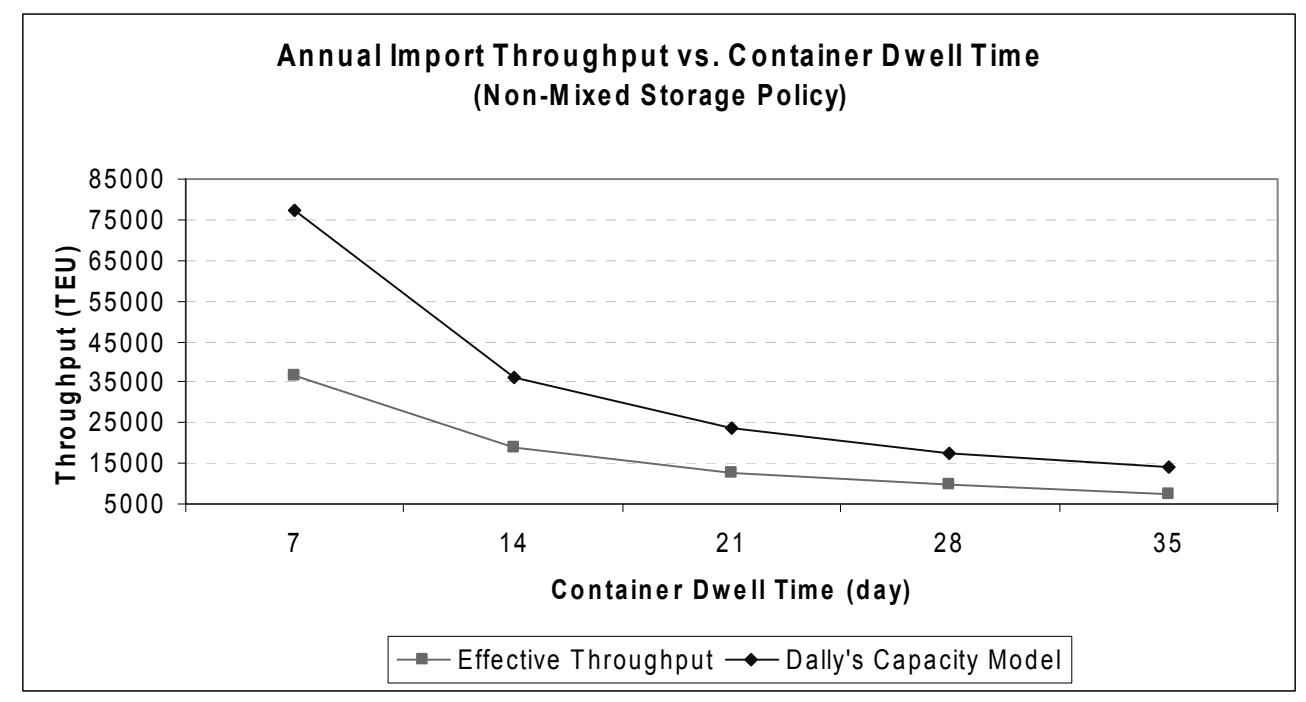

Figure 5. Effect of dwell time on annual import throughput under non-mixed storage policy

Figure 5 shows the relationship between annual effective import throughput and various import dwell periods under the non-mixed storage policy. The effective throughput values were obtained using equations 3 and 4, which can be conveniently solved for in Excel. Dally's capacity model (equation 2) is also shown in Figure 5 for comparison purposes. As expected, Dally's model yield higher throughput since his model represents the terminal's total capacity. Dally's suggested values of 0.75 and 1.4 were used for variables $\mathrm{W}$ and F, respectively. It can be seen that the shorter the dwell time the higher the throughput. Hence, dwell time can be considered "unproductive" since the container is not making progress toward its destination when it is waiting. It is clear that additional throughput can be achieved by simply reducing the container dwell time. However, in practice, dwell time cannot be completely eliminated because some amount of dwell time is expected whenever there is a change in transportation mode. For example, with imports paperwork needs to be processed for the release of a container (Higgins 2002), or if a container needs to be inspected by the U.S. Department of Agriculture (USDA) or Customs and Border Protection (CBP), it cannot leave the terminal until the inspection is completed.

The motivation for employing the non-mixed storage policy is to minimize rehandling, and the following experiment examines the gain in rehandling productivity.

In order to apply the proposed MCS method for a given stack height, a specific bay configuration must be assumed. Figure 6a shows the assumed bay configurations for average stack heights ranging from 1.0 to 3.5. This work considers 3.5 to be the maximum average stack height due to the need to reserve $(c-1)$ slots in a bay. Bay configuration 16 represents the full bay. 


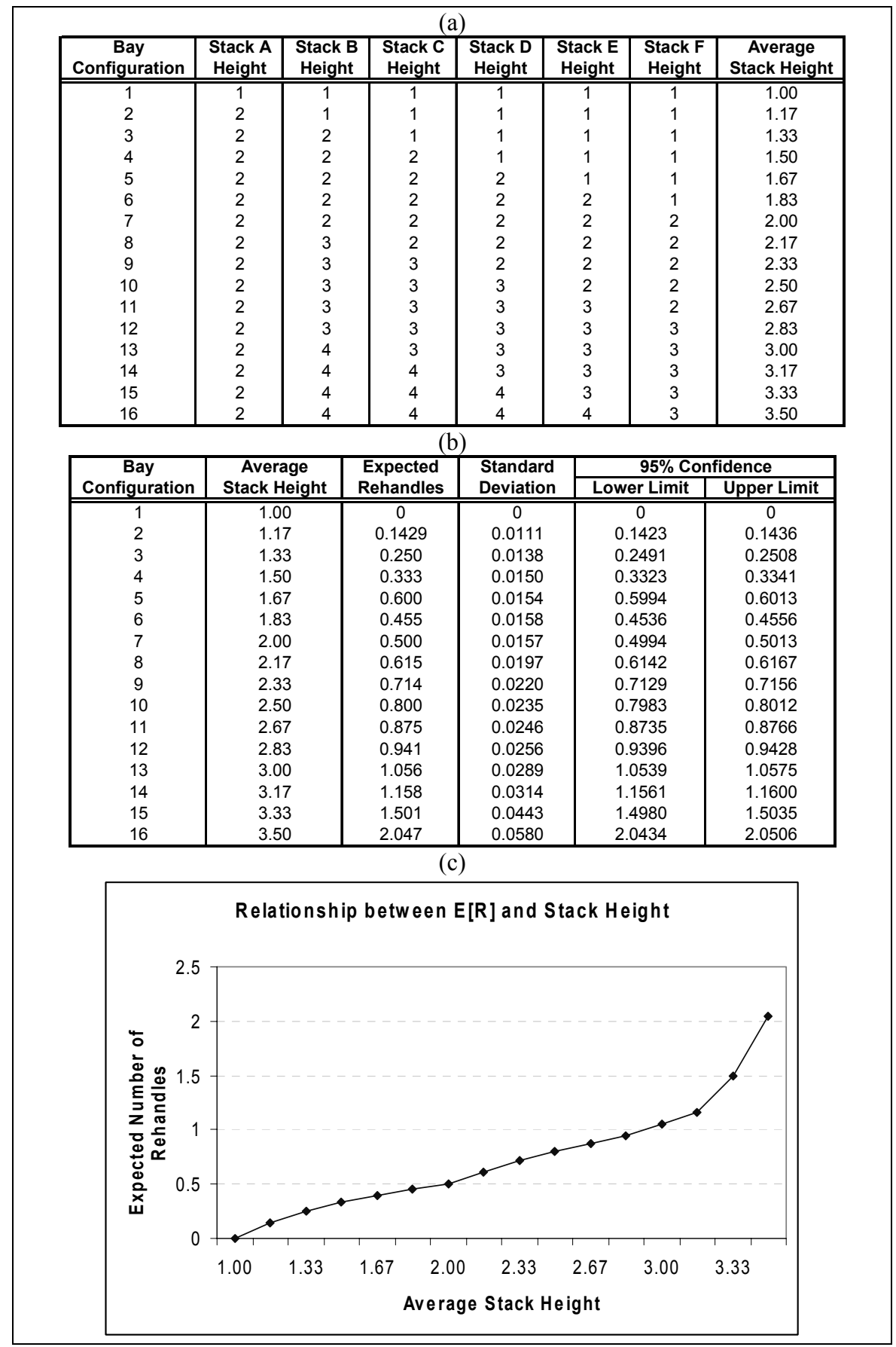

Figure 6. a) Top - Assumed bay configuration for a given average stack height,

b) Middle - Expected number of rehandles for a given average stack eight,

c) Bottom - Relationship between expected number of rehandles and stack height 
Figure $6 \mathrm{~b}$ shows the expected number of rehandles for various average stack heights. As expected, the number of handles increases as the stack height increases. It also makes sense that the standard deviation of the number of rehandles increases as the stack height increases. The $95 \%$ confidence interval highlights the tightness of the sample distribution.

Figure $6 \mathrm{c}$ shows that the relationship between the expected number of rehandles and average stack height is almost linear until the tail end where the number of rehandles rises sharply. This is because with bay configuration 15 and 16, extra moves are needed to keep slots A3 and A4 open.

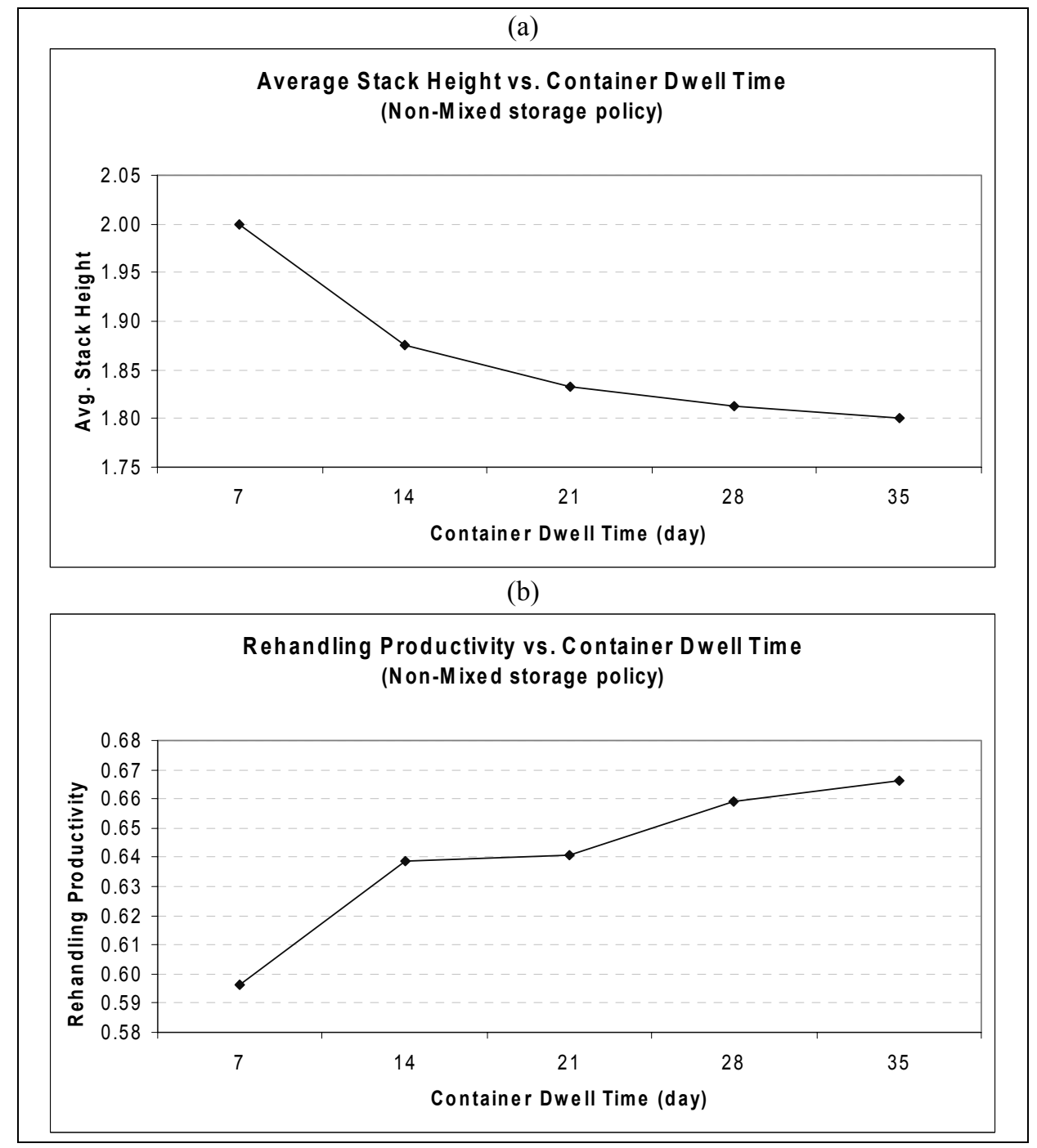

Figure 7. a) Top - Effect of dwell time on average stack height under non-mixed storage policy, b) Bottom - Effect of dwell time on rehandling productivity under non-mixed storage policy 
As shown in Figure 5, throughput decreases as dwell time increases. The lower the throughput, the fewer number of containers in the block, and hence, the lower the average stack height.

Figure 7a shows the corresponding average stack height for the throughput shown in Figure 5 for the different dwell times. The trend in which stack height decreases with increasing dwell time is identical to how throughput decreases.

Figure $7 \mathrm{~b}$ shows the corresponding gain in rehandling productivity as a result of lower average stack heights. The greatest gain in rehandling productivity occurs when dwell time is changed from 7 to 14 (increase of 7.04\%). The results indicate that as the container dwell time gets longer, the gain in rehandling productivity reduces. It can be seen that the rehandling productivity is inversely proportional to average stack height. The rehandling productivity trend in Figure $7 \mathrm{~b}$ is almost a mirror image of the stack height trend in Figure 7a.

To quantify the benefits of the gain in rehandling productivity, consider a terminal like BCT that delivers about 500,000 containers a year and the average rehandling time per move is about 25 seconds (Huynh, 2004). The improvement in rehandling productivity is 0.5965 to 0.6385 when dwell time is changed from 7 to 14 days. Using the introduced rehandling productivity equation (equation 1), it be can determined that the reduction in the annual number of import moves for RTGs is 55,138. This translates to a reduction in about 22,974 minutes of turn time per year for road trucks. The tradeoff for this gain is a throughput loss of 18,018 TEUs per year.

\section{Experiment Set 2 (mixed storage policy)}

Experiment parameters:

- 2 services: $D_{1}=0, D_{2}=2$, and $P_{1}=P_{2}=7$.

- 3 services: $D_{1}=0, D_{2}=2, D_{3}=4$, and $P_{1}=P_{2}=P_{3}=7$.

- 4 services: $D_{1}=0, D_{2}=2, D_{3}=4, D_{4}=6$, and $P_{1}=P_{2}=P_{3}=P_{4}=7$.

- Vary dwell time (7, 14, 21, 28, and 35).

- $F_{s}^{\text {imp }}(x)=B_{s}^{\text {imp }} /$ dwell time.

- $B_{s}^{i m p}=$ to be determined.

As mentioned, an alternative to increase throughput is to employ the mixed storage policy. Given the experiment parameters shown above, the second set of experiments examines the gain in throughput and loss of rehandling productivity when new imports are stacked on top of old ones. To determine how much throughput can be gained through the use of mixed storage policy, the optimal values of $B_{s}^{i m p}$ (number of import containers to be unloaded off of a vessel) can be obtained by solving the following optimization problem. If equations 3 and 4 are set up in Excel, finding the solution is straightforward with Excel's Solver. Note that the same starting point 
is used for each search. Specifically, the decision variable $B_{s}^{i m p}$ is set to zero before each optimization run.

Objective function: $\max \mathrm{Z}=\sum_{i=1}^{S} B_{i}$

Subject to:

1. $U(t)-D(t)<=693$ TEUs $, t=1,2, \ldots, 365$

2. $B_{i} \geq 0, i=1,2, \ldots, S$

Solving the above optimization problem for the two-services scenario for dwell time $=7$ days yields an annual import throughput of 45,898 TEUs. For the three-services scenario, the solution is 50,908 TEUs. For the four-services scenario, the solution is 55,383 TEUs.

Figure 8 shows how the maximum throughput is affected as dwell time increases. The results indicate that when the dwell time is low greater throughput can be achieved by mixing import containers from other services. Beyond 14 days, there is little unused space to utilize. Hence, there is not much difference in throughput between having two, three, or four services beyond 14 days.

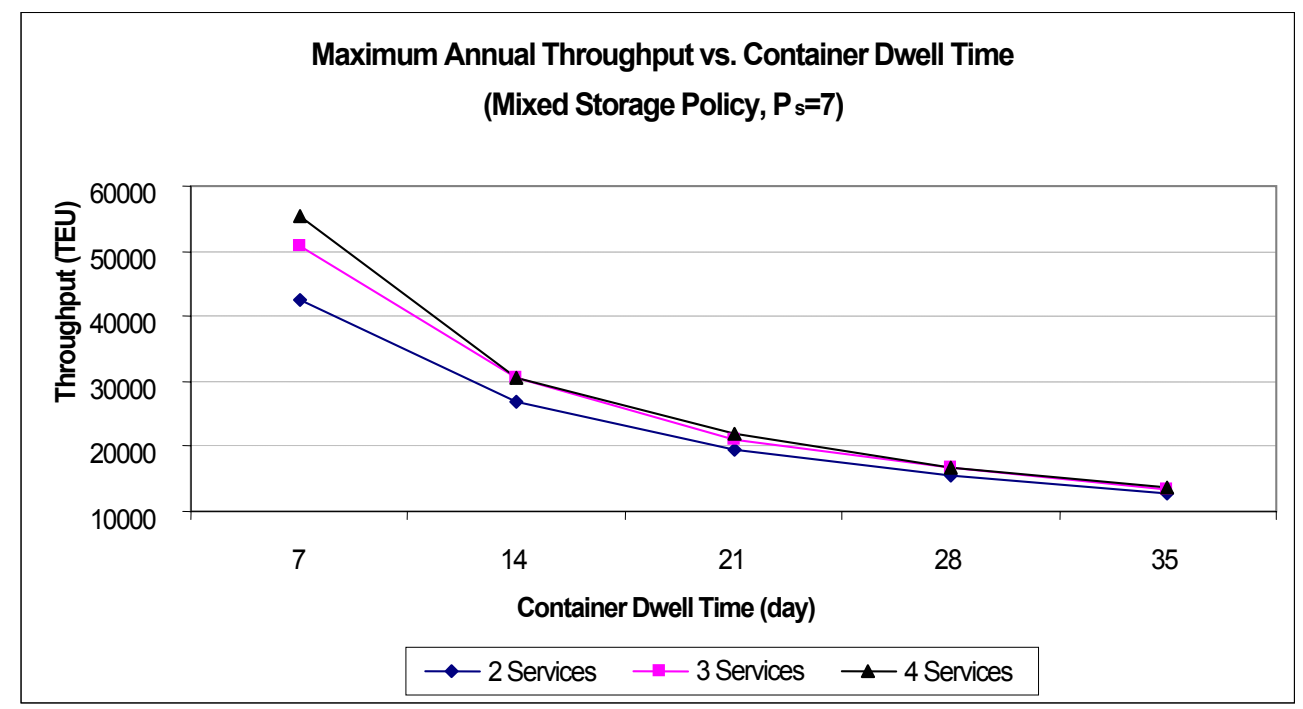

Figure 8. Effect of dwell time on maximum annual import throughput under mixed storage policy

With the mixed storage policy, new import containers are stacked on top of older arrivals. 
Hence, containers at the bottom of a stack are more likely to be selected for delivery. Suppose containers on tier 3 is twice as likely to be delivered as that of containers on tier 4, and containers in tier 2 is twice as likely to be delivered as containers on tier 3 , and containers in tier 1 is twice as likely to be delivered as containers on tier 2 . With this assumption, we would assign a weight of 1 to containers in tier $4\left(\lambda_{4}=1\right), 2$ to containers in tier $3\left(\lambda_{3}=2\right), 4$ to containers on tier $2\left(\lambda_{2}=4\right)$, and 8 to containers on tier $1\left(\lambda_{1}=8\right)$. Note that this assumption is simply a judgment call of what might be the likely case. There is no data to support this nor can it be proven because terminal operating data are not stored in a manner that would allow one to compute the number of rehandles a container had when it was delivered (based on the author's understanding of the Navis system used by BCT). Other values could easily be used for analysis.

If $x_{a c}$ is the event that a container in row a and tier $\mathrm{c}$ is selected for delivery, then

$$
P\left(x_{a c}\right)=\frac{\lambda_{c}}{n_{1} \lambda_{1}+n_{2} \lambda_{2}+n_{3} \lambda_{3}+n_{4} \lambda_{4}}
$$

where $n_{1}, n_{2}, n_{3}$, and $n_{4}$ are the number of containers in each respective tier.

(a)

\begin{tabular}{|c|c|c|c|c|c|}
\hline Bay & Average & Expected & Standard & \multicolumn{2}{|c|}{$95 \%$ Confidence } \\
\cline { 5 - 6 } Configuration & Stack Height & Rehandles & Deviation & Lower Limit & Upper Limit \\
\hline \hline 1 & 1.00 & 0 & 0 & 0 & 0 \\
2 & 1.17 & 0.154 & 0.0114 & 0.1532 & 0.1546 \\
3 & 1.33 & 0.286 & 0.0144 & 0.2849 & 0.2867 \\
4 & 1.50 & 0.400 & 0.0154 & 0.3989 & 0.4008 \\
5 & 1.67 & 0.500 & 0.0158 & 0.4991 & 0.5011 \\
6 & 1.83 & 0.588 & 0.0159 & 0.5868 & 0.5888 \\
7 & 2.00 & 0.667 & 0.0151 & 0.6658 & 0.6676 \\
8 & 2.17 & 0.811 & 0.0192 & 0.8096 & 0.8119 \\
9 & 2.33 & 0.947 & 0.0217 & 0.9461 & 0.9488 \\
10 & 2.50 & 1.077 & 0.0231 & 1.0753 & 1.0781 \\
11 & 2.67 & 1.200 & 0.0236 & 1.1982 & 1.2011 \\
12 & 2.83 & 1.317 & 0.0237 & 1.3155 & 1.3184 \\
13 & 3.00 & 1.470 & 0.0275 & 1.4681 & 1.4715 \\
14 & 3.17 & 1.619 & 0.0300 & 1.6166 & 1.6204 \\
15 & 3.33 & 2.235 & 0.0452 & 2.2321 & 2.2377 \\
16 & 3.50 & 3.070 & 0.0580 & 3.0661 & 3.0733 \\
\hline
\end{tabular}


(b)

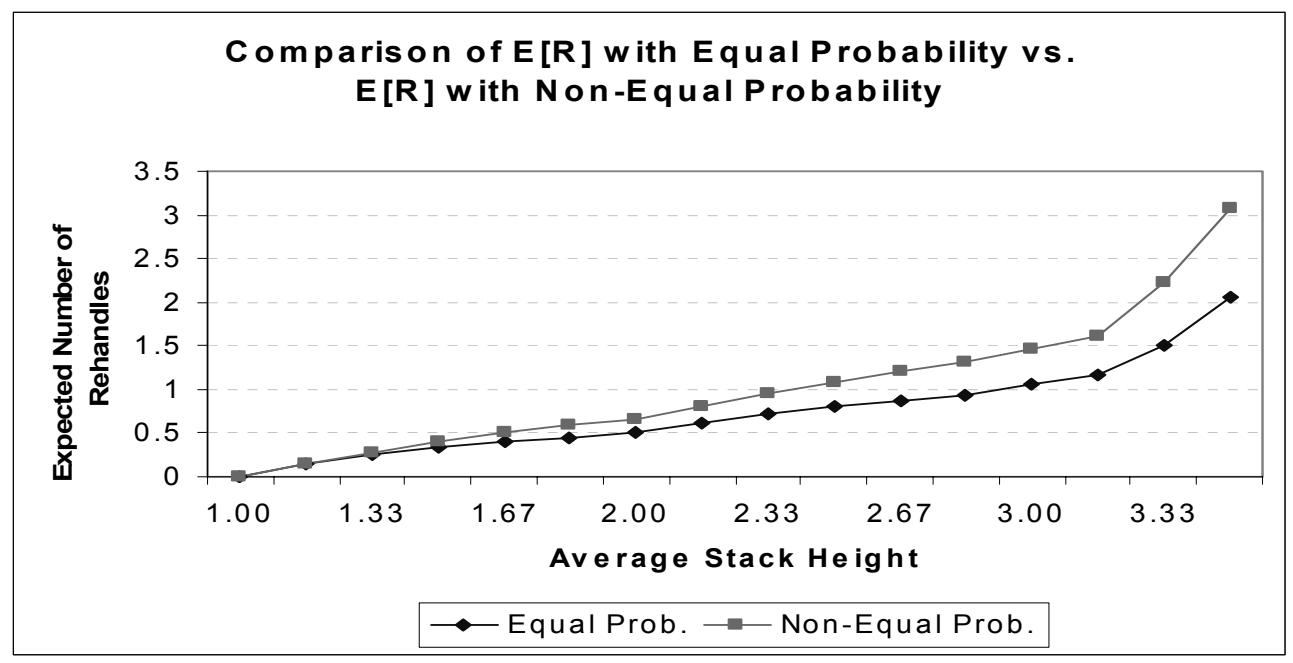

Figure 9. a) Top $-E[R]$ with non-equal probability of selecting a container,

b) Bottom-Comparison of $E[R]$ with equal probability versus $E[R]$ with non-equal probability

Figure 9a shows the expected number of rehandles for various stack heights with the newly considered probability of a container being picked. These values are noticeably higher compared to the expected number of rehandles with equal probability of selecting a container (shown in Figure $6 b$ ). These results make sense because when older containers at the bottom of a stack are more likely to be picked for delivery, there are more rehandling involved. As in the case with equal probability, the standard deviation increases as the stack height increases. Interestingly, the values of the standard deviation are about the same for both storage policies.

Figure $9 \mathrm{~b}$ compares the expected number of rehandles for the newly assumed probability against the typical assumption of equal probability. The gap between the two curves gets wider as the stack height increases. This result implies that when assuming equal probability, the expected number of rehandles will be lower than the true value by a wider margin when the storage density is higher.

Figure 10a shows how stack height increases as container dwell time increases for different number of services. The increase in stack height is minimal beyond 21 dwell days in all three scenarios. In the case with four services, the stack height is high to begin with (at 7 dwell days) and thus the dwell time effect is minimal compared to the two-services scenario. Figure 10b shows the corresponding reduction in rehandling productivity as the stack height increases. The results clearly indicate that the more mixing is done, the higher the throughput; however, rehandling productivity suffers. 
(a)

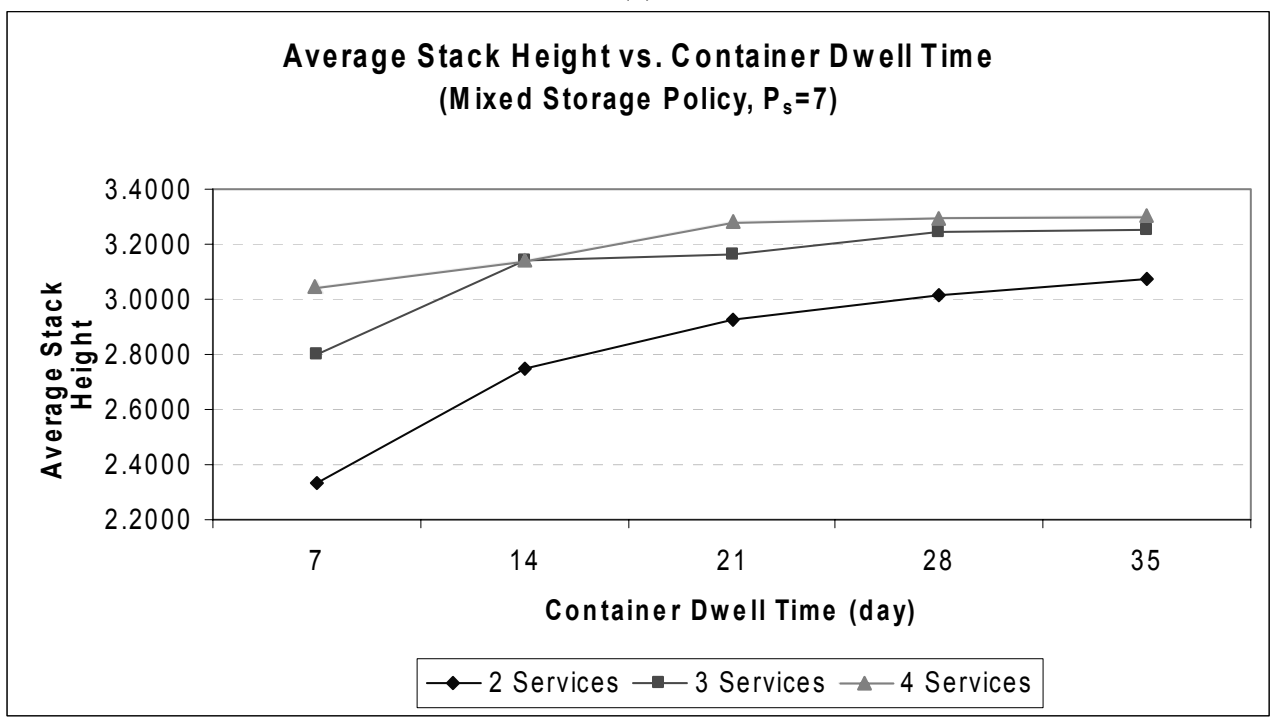

(b)

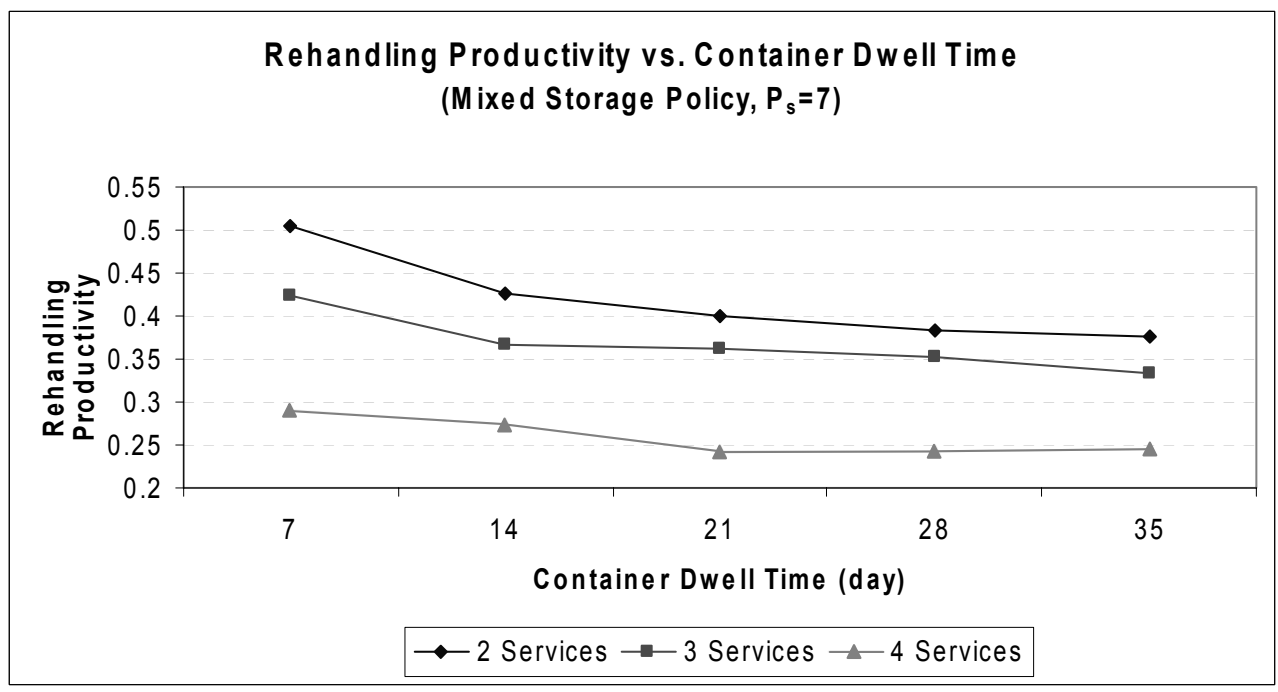

Figure 10. a) Top - Effect of dwell time on average stack height under mixed storage policy,

b) Bottom - Effect of dwell time on rehandling productivity under mixed storage policy

The gain in throughput for dwell time of seven days is 12,865 TEUs per year, going from two to four services. On the flip side, the rehandling productivity decrease to 0.29 from 0.50 . Again, using BCT's data, the reduction in rehandling productivity translate to an increase of about 724,138 import moves per year for RTGs and an additional 301,724 minutes of turn time per year for road trucks. 


\section{Summary and Conclusion}

This paper analyzes the effect of container dwell time on marine terminals' throughput and rehandling productivity. Simple expressions are derived to enable the evaluation of throughput and rehandling productivity, defined as the number of import deliveries divided by the total number of import moves. These expressions are derived based on how a typical container terminal operates, and they capture the relationship between container dwell time, throughput, and rehandling productivity. The expression to compute effective throughput considers the vessel schedule, demand, and dwell time. The expected number of rehandles (equation 5) is estimated using the Monte Carlo Simulation (MCS) technique. The use of the MCS method to evaluate equation 5 offers three main advantages. First, it allows us to make conclusions about the variance of the expected rehandles as a function of stack height and storage strategies. Second, it allows us to conveniently solve for ad hoc rehandling strategies. And third, it circumvents the need to make restrictive assumptions regarding the probability of containers of being delivered to road trucks.

The experiment results highlight the impact dwell time has on throughput and rehandling productivity. For the non-mixed storage policy, as throughput decreases with increasing dwell time, the average stack height also decreases. However, in the mixed storage policy, as throughput decreases with increasing dwell time, the average stack height actually increases. The higher the average stack height the higher the expected number of rehandles and the lower the rehandling productivity. Rehandling productivity drops rapidly as the average stack height approaches the maximum height due to the need to perform additional rehandling moves to keep the reserved slots open. The standard deviation of rehandles increases as the stack height increases. The standard deviations of rehandles are about the same between the two storage policies.

This paper sheds light on the subject of container dwell and its effect on throughput and rehandling productivity. Using the presented methods, port authorities and terminal operators are able to assess and quantify the benefits of their decisions regarding container free time. Once the assessment is completed, decision makers will be able to weigh the tradeoffs and make an informed decision.

\section{Acknowlegments}

The author would like to thank Mr. Robert Harrison for his feedback on earlier versions of this paper. This paper also benefitted from suggestions from two anonymous reviewers. The author would also like to thank Mr. Jeff Davis for his input on rehandling practice at Barbours Cut Terminal. The results and opinions expressed in this paper are solely those of the author. 


\section{References}

Barreto, H. and Howland, F. 2005. Introductory Econometrics: Using Monte Carlo Simulation with Microsoft Excel. Cambridge University Press.

Castilho B. and Daganzo, C. F. 1993. Handling Strategies for Import Containers at Marine Terminals. Transportation Research Part B. 27B(2): 151-166

Chu, C. Y. and Huang, W.C. 2005. Determining Container Terminal Capacity on the Basis of an Adopted Yard Handling System. Transport Reviews. 25(2): 181-199

Dally, H. K., Shrimpton, T. E., Marshall, J. K. and Maguire, F. J. 1977. Container Terminals - the Relationship Between Dwell Time and Throughput. National Ports Council Bulletin. 10: 1-14.

Dharmalingam, K. 1987. Design of Storage Facilities for Containers - A Case Study of Port Louis Harbour Mauritius. Ports and Harbors, September: 27-31.

Hicks, P. 2005. High density stacking. Container Management. Baltic Publishing Limited: 40-43.

Higgins, T., Dessouky, M. and Hall R. 2002. Port Operations: A Review of Practices. Final Report for Task 1.2.2.1 for the Center for Commercial Deployment of Transportation Technologies.

Huynh, N. 2006. Boosting Marine Container Terminals Throughput - A Survey of Strategies. Proceedings of the Transportation Research Board Annual Meeting. Paper: 06-2744. Huynh, N., C. M. Walton and J. Davis. 2004. Finding The Number Of Yard Cranes Needed To Achieve Desired Truck Turn Time At Marine Container Terminals. Transportation Research Record. 1873: 99-108.

Itsuro, W. 1991 . Container Terminal Storage Capacity Analysis. Container Age (April): 51-61.

Itsuro, W. 2001. Container Terminal Planning - A Theoretical Approach. Leatherhead, UK: World Cargo Publishing.

Kim, K. H. 1997. Evaluation of the number of rehandles in container yards. Computers \& Industrial Engineering. 32(4): 701-711

Leach, P. 2007. Black Magic. Journal of Commerce 8, Issue 27, Commonwealth Business Media Inc., Newark, New Jersey, July 8.

Lowenthal, Bill No. 2650 Chapter 1192, California State Assembly, 2002.

McDowell, E., Martin, G., Cho, D. and West, T. 1985. A Study of Maritime Container Handling. Oregon State University, Sea Grant College Program, Ads, Corvallis, Oregon 97331. 402: $1-10$

National Research Council. 1986. Improving Productivity in U.S. Marine Container Terminals. The National Academies Press.

The Week. 2005 . Journal of Commerce, June $27: 10$.

TR News. 2006. The Intermodal Container Era - History, Security and Trends, no. 246, Transportation Research Board, Washington D.C, September-October.

Watanabe, I. 1991. Characteristics and Analysis Method of Efficiencies of Container Terminal - an Approach to the Optimal Loading/Unloading Method, Container Age (March): 36-47. 
